\title{
Síndromes mielodisplásicas: Aspectos moleculares, laboratoriais e a classificação OMS 2008
}

\author{
Myelodysplasic symdrome: Molecular and laboratorial aspects and the 2008 WHO classification
}

Ana Carolina R. Moraes $^{1}$

Marley A. Licínioº

Lisiane Pagnussat ${ }^{2}$

Joanita A. G. Del Moral ${ }^{3}$

Maria Cláudia Santos- Silva

\begin{abstract}
As síndromes mielodisplásicas (SMDs) são caracterizadas por uma desordem clonal de células primordiais (stem cell) e hematopoese ineficaz que levam à displasia de uma ou mais linhagens celulares da medula óssea, citopenias periféricas e instabilidade genética, as quais aumentam o risco de transformação à leucemia mieloide aguda. Esse grupo heterogêneo de doenças hematopoéticas pode surgir como doença primária, que possui etiologia variada e não completamente definida, ou secundária ao tratamento quimioterápico ou radioterápico para outras neoplasias. $O$ surgimento e aprimoramento de tecnologias de diagnóstico geraram uma melhor compreensão dos processos envolvidos na gênese e evolução das SMDs, o que possibilitou o desenvolvimento de marcadores de diagnóstico e acompanhamentos cada vez mais precoces e específicos. No ano de 2008, a Organização Mundial da Saúde (OMS) redefiniu os critérios para classificação das SMDs, dividindo-as em sete subgrupos. Nessa classificação foram incluídos novos aspectos imunofenotípicos, genéticos, citomorfológicos e moleculares, o que tornou o domínio e o acesso a tecnologias de ponta imprescindíveis para a realização do diagnóstico das SMDs. Apesar dos avanços tecnológicos, alguns pontos, como as bases moleculares da transformação de SMD para LMA, ainda não estão bem esclarecidos, fazendo necessária a continuação de estudos nessa área. Diante disso, essa revisão busca compilar dados atuais dos aspectos moleculares e laboratoriais das SMDs. Rev. Bras. Hematol. Hemoter.
\end{abstract}

Palavras-chave: Síndrome mielodisplásica; Classificação OMS 2008; imunofenotipagem.

\section{Introdução}

As síndromes mielodisplásicas (SMDs) constituem um grupo heterogêneo de doenças hematopoéticas que acometem indivíduos de todas as idades, sobretudo adultos. ${ }^{1-4}$ As SMDs são originadas no microambiente medular, a partir de uma mutação somática das células progenitoras hema- topoéticas (stem cell), ${ }^{3,5}$ o que leva a uma desordem nas vias de sinalização intracelular, resultando em um aumento da apoptose nessas células. ${ }^{6,7}$ Dessa forma, essa hemopatia caracteriza-se por hematopoese ineficaz, com displasia de uma ou mais linhagens celulares da medula óssea (MO), citopenias periféricas, ${ }^{2,3}$ aumento do número de mieloblastos no sangue periférico (SP) e/ou $\mathrm{MO}^{8,9}$ e instabilidade genética. ${ }^{2,3,5}$

\footnotetext{
${ }^{1}$ Farmacêutica-Bioquímica.

${ }^{2}$ Aluna do Curso de Farmácia da Universidade Federal de Santa Catarina.

${ }^{3}$ Professora do Departamento de Clínica Médica da Universidade Federal de Santa Catarina.

${ }^{4}$ Professora do Departamento de Análises Clínicas da Universidade Federal de Santa Catarina.
}

Universidade Federal de Santa Catarina - Florianópolis-SC.

Correspondência: Maria Cláudia Santos-Silva

Laboratório de Análises Clínicas do Hospital Universitário - HU/Universidade Federal de Santa Catarina

Campus Universitário - Trindade

88040-970 - Florianópolis-SC - Brasil

Tel.: (+55 48) 3721-8146 / Fax: (+55 48) 3721-9542

E-mail:maclau@ccs.ufsc.br 
A presença da instabilidade genética aumenta o risco de a SMD evoluir para leucemia mieloblástica aguda (LMA), ${ }^{10-12}$ ou, em raros casos, para leucemia linfoblástica aguda (LLA). ${ }^{11,13}$

Quanto à sua etiologia, a SMD pode ser classificada como SMD primária ou de novo e secundária. A doença primária não possui uma etiologia totalmente elucidada, sabese que ela pode advir de infecções virais, exposição ao benzeno, radiações ionizantes ${ }^{6,8,14}$ e, mais raramente, de anormalidades congênitas. ${ }^{14,15}$ Alguns trabalhos relatam que mutações em genes que participam da via de sinalização celular e defeitos nos mecanismos de reparo de DNA são fatores de risco para o desenvolvimento de SMD de novo. ${ }^{12,16}$

A SMD secundária (SMD-t) é resultante do tratamento quimioterápico, principalmente com agentes alquilantes, ou radioterápico, ${ }^{6,15}$ e apresenta um curso clínico mais agressivo que a SMD de novo. O seu desenvolvimento, geralmente, ocorre de quatro a sete anos após a exposição inicial ao agente e corresponde a, aproximadamente, $10 \%$ do total de casos de SMD. ${ }^{6,17}$

Na SMD, os sintomas clínicos comumente encontrados são fadiga, palidez, fraqueza ${ }^{6,18}$ e dispneia. ${ }^{18}$ Além disso, podem-se observar infecções devido à leucopenia. ${ }^{18}$ Outros achados comuns, como púrpura e complicações hemorrágicas, são resultados da plaquetopenia e disfunção plaquetária presentes na maioria dos indivíduos com SMD. ${ }^{19}$ Como visto, os sinais e sintomas são inespecíficos, sendo assim o diagnóstico laboratorial é determinante.

Com o advento dos novos métodos de diagnóstico laboratorial, como a citometria de fluxo, o diagnóstico de SMD tornou-se mais evidente. Além disso, acredita-se que as melhorias na assistência médica geriátrica, associadas ao aumento da longevidade da população, também são responsáveis pelo aumento do número de novos casos de SMD. ${ }^{12,18}$

A incidência mundial de SMD é de 3 a 5/100.000 habitantes/ano e cresce exponencialmente com o avanço da idade, chegando a mais de 20/100.000 habitantes/ano na faixa etária superior a 70 anos. ${ }^{14}$ No Brasil, a incidência de SMD ainda é desconhecida e a realização de estudos epidemiológicos se faz necessária.

\section{Aspectos moleculares}

Como visto anteriormente, a hematopoese ineficaz na SMD deve-se a um microambiente medular anormal que induz à morte precoce das células progenitoras hematopoéticas $(\mathrm{CPH})$, por apoptose. ${ }^{6,720}$ Fisiologicamente, o processo de apoptose celular ocorre por duas vias de sinalização denominadas de vias intrínseca e extrínseca da apoptose, as quais são reguladas por fatores anti e pró-apoptóticos. ${ }^{6}$ A via intrínseca de sinalização celular da apoptose envolve a desregulação mitocondrial. Na SMD, a apoptose é marcada pelo acúmulo de ferro na forma de ferritina nas mitocôndrias dos sideroblastos, ${ }^{6,7}$ consequentemente leva à formação de espécies reativas de oxigênio, as quais alteram o potencial da membrana mitocondrial, culminando na liberação de citocromo-c e posterior ativação da via das caspases, o que acarreta a morte celular pela via intrínseca. ${ }^{6}$

Vários tipos de mutações, como monossomias ou deleções, são observadas na maioria dos pacientes com SMD, acarretando uma proliferação clonal das CPH na MO, as quais conferem vantagem proliferativa a essas células. ${ }^{12,16}$

A SMD pode evoluir para LMA. ${ }^{6,12}$ Normalmente, a diferenciação entre SMD e LMA não apresenta dificuldades. No entanto, em algumas situações, a diferenciação entre elas pode ser desafiadora, principalmente nos casos em que, ao diagnóstico, o paciente apresenta uma porcentagem de mieloblastos em SP e/ou MO entre 15\% e 19\%, uma história subclínica de $\mathrm{SMD}^{21}$ ou um quadro de LMA de novo com displasia de múltiplas linhagens., ${ }^{8,22}$ Outro desafio é determinar o momento em que um indivíduo com SMD evoluiu para um quadro de LMA e deve, portanto, ter seu tratamento alterado. O processo pelo qual essa evolução ocorre é ainda muito controverso e alguns critérios podem ser utilizados no diagnóstico diferencial (Tabela 1). ${ }^{6,10}$

Assim como a SMD, a LMA é uma doença clonal que apresenta hipercelularidade medular devido ao aumento da proliferação celular e redução da produção de células normais. No entanto, na LMA geralmente observa-se a redução das três linhagens celulares (eritroide, granulocítica e plaquetária), ${ }^{6}$ enquanto na SMD existe a diminuição de uma, duas ou três linhagens. ${ }^{2,6}$ Na SMD existe uma desordem na diferenciação celular e aumento da morte celular (apoptose), enquanto na LMA ocorre um bloqueio na diferenciação e morte celular reduzida. ${ }^{6}$ Outra característica que distingue a SMD da LMA é a presença de alterações cromossômicas específicas, como as translocações do tipo t(15; 17), t(8; 21) e t $(16 ; 16)$ que são vistas quase exclusivamente em casos de LMA. Já as aberrações inv(3), del(5q), del(5), del(7q) e/ou del(7) são vistas em ambas as neoplasias. Vale ressaltar que os casos de SMD que apresentam as alterações genéticas acima citadas, frequentemente evoluem para LMA em um curto período de tempo. ${ }^{6,12,14}$

Devido à heterogeneidade da patogênese da SMD, o seu curso clínico e prognóstico são altamente variáveis.

Tabela 1. Diferenças entre SMD e LMA ${ }^{6}$

\begin{tabular}{|c|c|c|}
\hline & SMD & LMA \\
\hline $\begin{array}{l}\text { Alterações } \\
\text { cromossômicas }\end{array}$ & $\begin{array}{c}\text { Deleção do } \\
\text { cromossoma } 5 \\
\text { e/ou } 7\end{array}$ & $\begin{array}{l}\mathrm{t}(8 ; 21) ; \mathrm{t}(16 ; 16) ; \\
\mathrm{t}(15 ; 17)\end{array}$ \\
\hline Morfologia & $\begin{array}{l}\text { Displasia de } \\
\text { núcleo e } \\
\text { citoplasma }\end{array}$ & $\begin{array}{c}\text { Normal, em alguns casos } \\
\text { bastonete de Auer }\end{array}$ \\
\hline Apoptose & Alta & Baixa \\
\hline $\begin{array}{l}\text { Diferenciação } \\
\text { celular }\end{array}$ & Desordem & Bloqueio \\
\hline
\end{tabular}


O Sistema Internacional de Escore Prognóstico (IPSS) das SMDs recebeu aceitação internacional para a estimativa do prognóstico de pacientes com SMD. No entanto, esse escore não é suficiente para auxiliar na escolha da intervenção terapêutica. Por isso, seria de grande auxílio no tratamento do paciente com SMD o estabelecimento de novos marcadores moleculares que reflitam claramente a progressão da doença.

Como visto, a regulação da apoptose é de extrema importância na patogênese e progressão das malignidades hematológicas. Devido a isto, muitos grupos têm pesquisado a utilização de proteínas reguladores da apoptose como novos marcadores moleculares de diagnóstico e prognóstico de SMD. ${ }^{23-26}$ Um estudo com 42 pacientes avaliou a expressão das proteínas inibidoras da apoptose (IAPs) em indivíduos com SMD e LMA secundária à SMD como marcador de diferenciação entre SMD e LMA de novo e marcador de evolução de SMD para LMA. Nesse trabalho, constatou-se que indivíduos com SMD e com LMA de novo apresentam um significativo aumento na expressão de survivina, cIAP1, NAIP e XIAP quando comparados com amostras controles de indivíduos normais. Ainda nesse estudo, foi observado que na SMD o aumento da expressão de cIAP1 é significativamente maior e da XIAP significativamente menor do que na LMA de novo, e que pacientes com LMA secundária à SMD possuíam baixa expressão de XIAP, quando comparados com indivíduos com a LMA de novo. ${ }^{26}$ Gianelli e cols. ${ }^{25}$ avaliaram a expressão da survivina em indivíduos com SMD como um marcador de prognóstico. Esse estudo demonstrou que a alta expressão de survivina está relacionada com uma SMD de baixo risco, enquanto na SMD de alto risco os níveis de expressão diminuem.

Os membros da família Bcl-2 são importantes reguladores da via da apoptose, apresentando tanto funções pró-apoptóticas quanto antiapoptóticas. ${ }^{27} \mathrm{~A}$ desregulação dos membros dessa família já foi demonstrada numa variedade de neoplasias hematológicas. ${ }^{28,29} \mathrm{Um}$ estudo comparou a expressão de membros pró-apoptóticos (Bax e Bad) e antiapoptóticos (Bcl-2 e Bcl$\mathrm{X}_{\mathrm{L}}$ ) da família Bcl-2 em progenitores CD34 na SMD constatando que, no seu estágio inicial, a SMD apresenta maiores níveis e Bax/Bad do que de Bcl-2/Bcl- $X_{L}$. Nesse mesmo trabalho, evidenciou-se uma significativa diminuição dos membros próapoptóticos em relação aos antiapoptóticos durante a progressão da doença. ${ }^{30}$
Além das proteínas relacionadas à regulação das vias da apoptose, outras proteínas estão sendo investigadas como possíveis marcadores de prognóstico e progressão da SMD. A Bmi-1 é uma proteína necessária para a regulação da renovação de células hematopoéticas em adultos. Grupos demonstraram que a superexpressão do gene Bmi1 pode estar relacionada com a proliferação de células neoplásicas ${ }^{31-34} \mathrm{e}$ progressão de malignidades hematopoéticas. ${ }^{35-38}$ Mihara et al., ${ }^{24} \mathrm{em}$ um estudo com 51 pacientes recém-diagnosticados com SMD ou LMA secundária à SMD, demonstraram que a positividade de Bmi-1 em células CD34+ correlacionase positivamente com o IPSS, sugerindo que a positividade dessa proteína em células CD34+ seja um preditor de progressão e prognóstico da SMD. O prognóstico desfavorável apresentado pelos pacientes com LMA secundária à SMD torna o diagnóstico diferencial dessa ainda mais imprescindível. Esse prognóstico desfavorável pode estar relacionado às proteínas de resistência a múltiplas drogas (MDR) ${ }^{39,40}$ e estudos têm avaliado a possível utilização dessas proteí-

Tabela 2. Alterações hematológicas periféricas observadas na $\mathrm{SMD}^{3}$

\begin{tabular}{cccc}
\hline $\begin{array}{c}\text { Série } \\
\text { Eritroide }\end{array}$ & $\begin{array}{c}\text { Série } \\
\text { granulocítica }\end{array}$ & $\begin{array}{c}\text { Série } \\
\text { Monocítica }\end{array}$ & $\begin{array}{c}\text { Série } \\
\text { megacariocítica }\end{array}$ \\
\hline $\mathrm{Hb}^{\mathrm{a}}<11 \mathrm{~g} / \mathrm{d}$ & $\mathrm{N}^{\mathrm{b}}<1.500 / \mathrm{mm}^{3}$ & $\mathrm{M}^{\mathrm{C}}>1.000 / \mathrm{mm}^{3}$ & $\mathrm{P}^{\mathrm{d}}<100.000 / \mathrm{mm}^{3}$ \\
reticulocitopenia & Hipogranulação & $\begin{array}{c}\text { Presença de } \\
\text { promonócitos }\end{array}$ & \\
$\mathrm{VCM}^{\mathrm{e}}>100 \mathrm{fl}$ & Pseudo-Pelger-Hüet & $\begin{array}{c}\text { Vacuolizações } \\
\text { Citoplasmáticas }\end{array}$ & \\
Anisocitose & Fragmentação da & \\
Pecilocitose & Cromatina & \\
Presença de & \\
Anisocromia & mieloblastos & \\
Policromasia & & \\
Pontilhado basófilo & & \\
Eritroblastos & & \\
\hline
\end{tabular}

${ }^{\mathrm{a}} \mathrm{Hb}=$ hemoglobina. ${ }^{\mathrm{b}} \mathrm{N}=$ neutrófilos $.{ }^{\mathrm{c}} \mathrm{M}=$ monócitos. ${ }^{\mathrm{d}} \mathrm{P}=$ plaquetas

$\mathrm{VCM}=$ volume celular médio

Tabela 3. Alterações morfológicas observadas nas células de linhagem eritroide e mieloide na $\mathrm{MO}$ de pacientes com $\mathrm{SMD}^{2,3,18}$

\begin{tabular}{|c|c|c|}
\hline Série eritroide & Série granulocítica & Série monocítica \\
\hline $\begin{array}{l}\text { Assincronismo maturativo } \\
\text { núcleo/citoplasmático }\end{array}$ & $\begin{array}{l}\text { Assincronismo maturativo } \\
\text { núcleo/citoplasmático }\end{array}$ & Presença de promonócitos \\
\hline Formas megaloblastoides & Formas megaloblastoides & $\begin{array}{l}\text { Vacuolizações } \\
\text { citoplasmáticas }\end{array}$ \\
\hline Falhas de hemoglobinização & Disgranulações & Presença de atipias \\
\hline Mitoses anômalas & Formas imaturas bizarras & $\begin{array}{l}\text { Presença de formas } \\
\text { aberrantes }\end{array}$ \\
\hline Vacuolização citoplasmática & Presença de atípicas & \\
\hline $\begin{array}{l}\text { Presença de formas } \\
\text { aberrantes }\end{array}$ & $\begin{array}{l}\text { Mieloblastos com ou sem } \\
\text { bastonete de Auer }\end{array}$ & \\
\hline Sideroblastos anelares & & \\
\hline
\end{tabular}


Tabela 4. Anormalidades fenotípicas observadas em células hematopoéticas na SMD por citometria de fluxo $2,3,48,51$

Progenitores mieloides Cd34+

Aumento da contagem absoluta e relativa de células CD34+

Expressão de CD11b e/ou CD15

Perda da expressão de CD13, CD33 ou HLA-DR

Expressão de antígenos linfoides (CD5, CD7, CD19 ou CD56)

Diminuição da expressão de CD45

Aumento ou diminuição anormal da intensidade de CD34

Diminuição anormal da expressão de CD38

Aumento da expressão CD2++

Progenitores linfoides B CD34+ (CD34+/CD10+)

Diminuição da contagem absoluta e relativa de células CD34+/CD10+

Série Neutrofílica

Hipogranularidade evidenciada pelo SSC

Diminuição da expressão de CD45

Padrão de relação CD13/CD16 anormal

Razão HLA-DR/CD11b anormal

Padrão de relação CD11b/CD16 anormal

Assincronismo maturativo

Perda da expressão de CD13 ou CD33

Expressão de CD34 ou CD56+

Expressão de antígenos linfoides

Monócitos

Anormalidade na relação da expressão entre HLA-DR, CD11b, CD13, CD14 e CD33

Perda da expressão de CD13, CD14, CD16 ou CD33

Expressão de CD34 ou CD56

Expressão de antígenos linfoides (com exceção do CD4)

Série Eritroide

Expressão do CD34

Expressão anormal de CD45, CD71, CD117, CD235a e/ou Glicoforina A

Série Megacariocítica

Aumento da contagem absoluta e relativa de células megacariocíticas

nas de resistência como marcadores de diagnóstico das SMDs. ${ }^{41-45}$ Um estudo que avaliou a expressão de três proteínas de resistência (glicoproteína-P - P-gp, proteína de resistência a múltiplas drogas - MRP e a lung resistance protein - LRP), relatou que a expressão de P-gp e LRP são mais frequentes em pacientes com SMD quando comparados aos portadores de LMA de novo. ${ }^{45}$ No entanto, em outro trabalho, Suárez e cols ${ }^{41}$ demonstraram que não houve diferença significativa na expressão de P-gp, MRP e LRP entre pacientes com SMD e LMA de novo.

Esses resultados refletem a discordância entre os trabalhos encontrados na literatura. Muitos autores atribuem esses resultados contraditórios às diferenças metodológicas existentes. ${ }^{42,46}$
Tabela 5. Critérios de diagnóstico de $\mathrm{SMD}^{\text {a 2,3 }}$

Grupo A - Primeiros critérios hematológicos avaliados

Citopenia constante em uma ou mais linhagens: eritroide (hemoglobina $<11 \mathrm{~g} / \mathrm{dL}$ ); neutrofílica (neutrófilos $<1.500 / \mathrm{mm}^{3}$ megacariocítica (plaquetas $<100.000 / \mathrm{mm}^{3}$ )

Exclusão de todas as outras doenças hematopoéticas

Grupo B - Critérios decisivos para SMD

Displasia em, pelo menos, $10 \%$ de todas as células de uma das seguintes linhagens da medula óssea: eritroide e/ou neutrofilica e/ou megacariocítica; ou > $15 \%$ de sideroblastos

Presença de $5-19 \%$ de blastos na medula óssea

Alterações cromossômicas típicas de $\mathrm{SMD}^{\mathrm{b}}$

Grupo C - Cocritérios para pacientes que obedecem "A", mas não "B"

Anormalidade fenotípica das células da medula óssea indicativa de uma população monoclonal da série eritroide e/ou mieloide

Alterações moleculares na via de sinalização celular

Perda parcial ou total dos antígenos de maturação e/ou presença de células imaturas no SP

${ }^{\mathrm{a}} \mathrm{O}$ diagnóstico de SMD é estabelecido quando são preenchidos os dois critérios do grupo "A" e, pelo menos, um critério do grupo "B"; b As alterações cromossômicas mais frequentes envolvem os cromossomos: 5, 7, 8 e 20

\section{Aspectos laboratoriais no diagnóstico de SMD}

O diagnóstico das SMDs é baseado nos resultados do hemograma completo, mielograma, imunofenotipagem e citogenética.

Na avaliação das alterações hematológicas periféricas deve-se considerar a presença de citopenia(s) sustentada(s) por 4-8 semanas, além de alterações nas séries eritroide, granulocítica, monocitária e/ou megacariocítica, como pode ser observado na Tabela 2.

Na maioria dos pacientes com SMD, a MO apresentase hipercelular e se podem observar células displásicas (Tabela 3). As displasias só devem ser consideradas quando presentes em $10 \%$ ou mais das células de uma ou mais séries hematopoéticas.

A imunofenotipagem realizada por citometria de fluxo tem sido utilizada para detectar expressões anormais de antígenos celulares relacionados à linhagem e maturação das diversas séries hemopoéticas e para verificar aumento de marcadores pró-apoptóticos nessas células. Além disso, é utilizada para detectar a expressão de células CD34+ e CD45 ${ }^{+}{ }^{3,47}$ Recentemente, vários trabalhos mostram a importância das características imunofenotípicas, quali e quantitativas das células progenitoras hematopoéticas CD34+, células mieloides e monócitos maduros, analisadas por citometria de fluxo. ${ }^{2,48}$

A perda parcial ou total de um antígeno em $10 \%$ ou mais das células em uma população de interesse, bem como a parada maturativa, a assincronia na expressão da maturação 
de dois antígenos e a presença de expressões aberrantes são alterações específicas da SMD. ${ }^{49,50}$ Como na SMD a linhagem mais acometida é a mieloide, é de extrema importância a investigação das marcações de mieloblastos, como os anticorpos HLA-DR, CD33, CD13, CD11b, CD117, CD15, CD16 e CD45. ${ }^{3,47,49}$ Na SMD, podem ser observadas alterações fenotípicas características nas células da série mieloide e eritroide, como pode ser visto na Tabela 4.

O estudo das alterações cromossômicas na SMD auxilia no diagnóstico, na classificação, na escolha terapêutica e no prognóstico. ${ }^{52,53,54}$ As anomalias cromossômicas em SMD são clonais, não ocorrem ao acaso e constituem-se, em geral, na perda de material genético, o que sugere a inativação de genes supressores tumorais necessários para o desenvolvimento de células mieloides normais. As alterações cromossômicas mais frequentes na SMD envolvem os cromossomos 5, 7, 8, 11, 13, 17, 20, 21 e X..$^{52,53}$ Com base na citogenética, as alterações cromossômicas da SMD podem ser divididas em cariótipo normal, perdas isoladas, translocações balanceadas e cariótipos complexos (três ou mais anomalias). ${ }^{52,53}$ As deleções ou monossomias representam as alterações genéticas mais frequentes na SMD. O grupo de cariótipo complexo apresenta um acúmulo de alterações progressivas e maior agressividade, ${ }^{52,55}$ o que torna necessária a repetição periódica do cariótipo, pois cerca de 30\% dos pacientes desenvolvem alterações adicionais com o passar do tempo e $12 \%$ dos casos com cariótipo normal ao diagnóstico adquirem anomalias subsequentes, apresentando um prognóstico desfavorável quando comparados com indivíduos que permanecem com cariótipo imutável..$^{55}$

Segundo o Consenso de Valent e cols, ${ }^{2}$ o diagnóstico inicial de SMD deve ser estabelecido após análise de critérios pertencentes a dois grupos (A e B), no qual serão classificados como SMD aqueles casos que preencherem os dois critérios do grupo "A", e pelo menos, um critério do grupo "B" (Tabela 5)., ${ }^{2,3}$

Para o diagnóstico de SMD deve-se excluir a presença de doenças não clonais que possuam características semelhantes às observadas na SMD. ${ }^{3}$ Portanto, faz parte da investigação laboratorial a dosagem de vitamina B12, ácido fólico, hormônios tireoidianos, ferro sérico, ferritina; determinação da capacidade latente de ligação de ferro; pesquisa de Coombs

Tabela 6. Classificação da OMS para SMD ${ }^{14}$

\begin{tabular}{|c|c|c|}
\hline Subgrupo & Achados em Sangue periférico & Achados em Medula óssea \\
\hline $\begin{array}{l}\text { Citopenias refratárias com displasia } \\
\text { de única linhagem (CRDU): } \\
\text { Anemia refratária (AR); } \\
\text { Neutropenia refratária (NR); } \\
\text { Trombocitopenia refratária (TR) }\end{array}$ & $\begin{array}{l}\text { Citopenia única ou bicitopenia }{ }^{\mathrm{a}} \\
\text { Blastos ausentes ou raros }(<1 \%)^{\mathrm{b}}\end{array}$ & $\begin{array}{l}\text { Displasia de única linhagem: } \\
\geq 10 \% \text { das células em uma linhagem mieloide }<5 \% \text { de } \\
\text { blastos }<15 \% \text { de sideroblastos em anel }\end{array}$ \\
\hline $\begin{array}{l}\text { Anemia refratária com sideroblastos } \\
\qquad \text { em anel (ARSA) }\end{array}$ & Anemia Ausência de blastos & $\begin{array}{c}\text { Displasia apenas na linhagem eritróide }<5 \% \text { de blastos } \\
\geq 15 \% \text { de sideroblastos em anel }\end{array}$ \\
\hline $\begin{array}{l}\text { Citopenia refratária com displasia de } \\
\text { múltiplas linhagens (CRDM) }\end{array}$ & $\begin{array}{l}\text { Citopenia(s) Blastos ausentes ou raros } \\
(<1 \%)^{\mathrm{b}} \text { Ausência de bastonete de Auer } \\
\text { Monócitos }<1.000 / \mathrm{mm}^{3}\end{array}$ & $\begin{array}{c}\text { Displasia em } \geq 10 \% \text { das células em duas ou mais } \\
\text { linhagens mieloides }<5 \% \text { de blastos. Ausência de } \\
\text { bastonete de Auer } 15 \% \text { de sideroblastos em anel }\end{array}$ \\
\hline $\begin{array}{l}\text { Anemia refratária com excesso de } \\
\text { blastos-1 (AREB-1) }\end{array}$ & $\begin{array}{l}\text { Citopenia(s) }<5 \% \text { de blastos }{ }^{b} \\
\text { Ausência de bastonete de Auer } \\
\text { Monócitos }<1.000 / \mathrm{mm}^{3}\end{array}$ & $\begin{array}{l}\text { Displasia de única ou múltiplas linhagens } \\
5 \text { a } 9 \% \text { de blastos } \\
\text { Ausência de bastonete de Auer }\end{array}$ \\
\hline $\begin{array}{l}\text { Anemia refratária com excesso de } \\
\text { blastos-2 (AREB-2) }\end{array}$ & $\begin{array}{l}\text { Citopenia(s) } 5 \text { a } 19 \% \text { de blastos } \\
\text { Bastonete de Auer presente ou não } \\
\quad<1 \times 10^{9} / L \text { de monócitos }\end{array}$ & $\begin{array}{l}\text { Displasia de única ou múltiplas linhagens } \\
\qquad 5 \text { a } 19 \% \text { de blastos } \\
\text { Bastonete de Auer presente ou nãoc }\end{array}$ \\
\hline $\begin{array}{l}\text { Síndrome mielodisplásica - não } \\
\text { classificável (SMD-NC) }\end{array}$ & Citopenias $\leq 1 \%$ de blastos ${ }^{b}$ & $\begin{array}{c}\text { Displasia em }<10 \% \text { das células em uma ou mais } \\
\text { linhagem mieloide quando acompanhada de } \\
\text { anormalidades citogenéticas presuntivas de } \mathrm{SMD}^{\mathrm{d}} \\
\qquad 5 \% \text { de blastos }\end{array}$ \\
\hline $\begin{array}{l}\text { Síndrome mielodisplásica associada } \\
\qquad \text { com del }(5 q) \text { isolada }\end{array}$ & $\begin{array}{l}\text { Anemia } \\
\text { Contagem de plaquetas normal ou } \\
\text { elevada } \\
\text { Blastos ausentes ou raros }(<1 \%)\end{array}$ & $\begin{array}{l}\text { Normo a hipercelularidade megacariocítica } \\
\text { núcleo hipolobulado } \\
\quad<5 \% \text { de blastos } \\
\text { Anormalidade citogenética: del }(5 q) \text { isolada }\end{array}$ \\
\hline
\end{tabular}

${ }^{a}$ Bicitopenia pode ser observada ocasionalmente. Casos com pancitopenia devem ser classificados com SMD-NC

b Se a porcentagem de mieloblastos na $\mathrm{MO}$ for $<5 \%$, mas existirem 2 a $4 \%$ de mieloblastos no SP, deve-se classificar como AREB-1.

Casos de CRDU e CRDM com $1 \%$ de mieloblastos no SP devem ser classificados como MDS-NC.

${ }^{c}$ Casos com bastonete de Auer e $<5 \%$ de mieloblastos no SP e $<10 \%$ na MO devem ser classificados como AREB-2

d Mais frequentes: -7 ou del(7q), -5 ou del( $5 q), i(17 q)$ ou $t(17 p)$, del(11q), del(12p) ou t(12p), -13 ou t(13q), t(11;16)(q23;p13.3). 
direto, deficiência de CD55 e CD59, disfunções metabólicas por insuficiência hepática ou renal; e sorologia para hepatite B e C, Vírus da Imunodeficiência Humana (HIV) e fator antinuclear (FAN). ${ }^{3,56}$ São considerados fatores de exclusão absolutos a exposição recente a agentes tóxicos ou compostos citostáticos, a deficiência de vitamina B12 ou ácido fólico e o uso recente de fatores de crescimento hematopoético. ${ }^{6,56}$

\section{Classificação dos subtipos de SMD-OMS 2008}

A primeira classificação para SMD foi proposta pelo Grupo Cooperativo Franco-Americano-Britânico (FAB). Posteriormente, houve uma reavaliação dessa classificação e, no ano de 2001, foi instituída a classificação da Organização Mundial da Saúde (OMS), que utiliza dados imunofenotípicos, genéticos, clínicos, citomorfológicos e citoquímicos para dividir a SMD em oito subgrupos. ${ }^{2,3}$ No ano de 2008, a classificação da OMS foi reformulada, abrangendo, atualmente, sete subgrupos como mostra a Tabela $6 .{ }^{14}$

Nas SMDs existem fatores clínicos e laboratoriais que podem ser utilizados para determinação do prognóstico. Os principais fatores prognósticos avaliados são: idade, porcentagem de blastos medulares, número de linhagens com citopenia periférica, número de linhagens hematopoéticas displásicas, níveis séricos de lactato desidrogenase (LDH), imunofenotipagem, expressão gênica molecular, dependência transfusional e citogenética. ${ }^{9,57}$

\section{Considerações finais}

Devido às características heterogêneas da SMD, o seu diagnóstico nem sempre é simples e exige do profissional de saúde, além dos conhecimentos sobre características laboratoriais, critérios diagnósticos e avaliação de prognóstico; o conhecimento na área de biologia molecular. O domínio e o acesso a tecnologias de ponta são atualmente imprescindíveis, uma vez que, segundo a OMS, o diagnóstico e classificação das SMDs não são possíveis sem uma correta avaliação imunofenotípica por citometria de fluxo, e citogenética por biologia molecular.

\footnotetext{
Abstract

Myelodysplastic syndromes (MDSs) are characterized by a stem cell clonal disorder and ineffective hematopoiesis which causes dysplasia in one or more bone marrow hematopoietic cell lineages, peripheral cytopenia and genetic instability with enhanced risk to transform into acute myeloid leukemia (AML). This heterogeneous group of hematopoietic diseases can develop as primary diseases, which posses a variable and not completely defined etiology, or as secondary to chemotherapy or radiotherapy for other neoplasias. The evolution of diagnostic tests has improved comprehension of the process involved in the genesis and evolution of MDSs, making the development of earlier and more specific tests for diagnosis and
}

follow ups possible. In 2008, the World Health Organization (WHO) redefined the criteria for the classification of MDSs, dividing them into seven subgroups. This classification included new immunophenotypic, genetic, cytomorphologic and molecular features, which are essential for the diagnosis of MDSs and for a better comprehension of the disease. Despite technological advances, some details, such as the molecular basis of the transformation of MDS to AML, are still not completely understood, which makes further studies in this field necessary. Hence, the objective of this review is to make a compilation of recent molecular and laboratory aspects of MDS. Rev. Bras. Hematol. Hemoter.

Key words: Myelodysplasic syndrome; WHO Classification 2008; immunophenotyping.

\section{Referências Bibliográficas}

1. Souto EX. Tratamento de suporte e quelação de ferro em pacientes com síndromes mielodisplásicas. Rev. Bras. Hematol. Hemoter. 2006;28(3):204-209.

2. Valent P, Horny HP, Bennett JM, Fonatsch C, Germing U, Greenberg $\mathrm{P}$, et al. Definitions and standards in the diagnosis and treatment of the myelodysplastic syndromes: Consensus statements and report from a working conference. Leuk Res. 2007;31(6):727-36.

3. Loken MR, van de Loosdrecht A, Ogata K, Orfao A, Wells DA. Flow cytometry in myelodysplastic syndromes: report from a working conference. Leuk Res. 2008;32(1):5-17.

4. Lopes LF, Lorand-Metze I, Mendes WL, Seber A, Melo LM. Síndrome mielodisplásica na infância. Rev. Bras. Hematol. Hemoter. 2006; 28(3):226-37.

5. Steensma DP, Bennett JM. The myelodysplastic syndromes: diagnosis and treatment. Mayo Clin Proc. 2006;81(1):104-30.

6. Corey SJ, Minden MD, Barber DL, Kantarjian H, Wang JC, Schimmer AD. Myelodysplastic syndromes: the complexity of stem-cell diseases. Nat Rev Cancer. 2007;7(2):118-29.

7. Malcovati L, Cazzola M. Myelodysplastic/myeloproliferative disorders. Haematologica. 2008;93(1):4-6.

8. Jaffe ES, Harris NL, Stein H, Vardiman JW. World Health Organization Classification of Tumours: Pathology and Genetics of Tumours of Haematopoietic and Lymphoid Tissues. 2001, Lion: IARC Press. 352

9. Varma N, Varma S. Proliferative indices, cytogenetics, immunophenotye and other prognostic parameters in myelodysplastic syndromes. Indian J Pathol Microbiol. 2008; 51 (1):97-101.

10. Bacher U, Haferlach T, Kern W, Haferlach C, Schnittger S. A comparative study of molecular mutations in 381 patients with myelodysplastic syndrome and in 4130 patients with acute myeloid leukemia. Haematologica. 2007;92(6):744-52.

11. Vidal DO, Lopes LF, Valera ET. Drug resistance and methylation in myelodysplastic syndrome. Curr Pharm Biotechnol. 2007;8 (2):77-81.

12. Owen C, Barnett M, Fitzgibbon J. Familial myelodysplasia and acute myeloid leukaemia - a review. Br J Haematol. 2008;140 (2):123-32.

13. Disperati P, Ichim CV, Tkachuk D, Chun K, Schuh AC, Wells RA. Progression of myelodysplasia to acute lymphoblastic leukaemia: implications for disease biology. Leuk Res. 2006;30(2):233-9.

14. Swerdlow SH, Campo E, Harris NL, Jaffe ES, Pileri SA, Stein H, Thiele J, Vardiman JW. WHO Classification of Tumours of Haematopoietic and Lymphoid Tissues. 4 ed. 2008, Geneva: WHO Press. 439 
15. Bortolheiro TC. Classificação morfológica das síndromes mielodisplásicas: da classificação Franco-Americana-Britânica (FAB) à classificação da Organização Mundial da Saúde (OMS). Rev. Bras. Hematol. Hemoter. 2006;28(3):194-7.

16. Chauffaille MLLF. Alterações moleculares em síndrome mielodisplásica. Rev. Bras. Hematol. Hemoter. 2006;28(3):188-93.

17. Pinheiro RF, Chauffaille MLLF. Síndrome mielodisplásica secundária à quimio ou radioterapia: SMD relacionada ao tratamento. Rev. Bras. Hematol. Hemoter. 2006;28(3):201-3.

18. Catenacci DV, Schiller GJ. Myelodysplasic syndromes: a comprehensive review. Cancer. 2007;109(9):1705-14.

19. Kantarjian H, Giles F, List A, Lyons R, Sekeres MA, Pierce S, et al. The incidence and impact of thrombocytopenia in myelodysplastic syndromes. Cancer 2007;109(9):1705-14.

20. Economopoulou C, Pappa V, Kontsioti F, Papageorgiou S, Kapsimali V, Papasteriadi C, et al. Analysis of apoptosis regulatory genes expression in the bone marrow (BM) of adult de novo myelodysplastic syndromes (MDS). Leuk Res. 2008; 32(1):61-9.

21. Larson RA. Is secondary leukemia an independent poor prognostic factor in acute myeloid leukemia? Best Pract Res Clin Haematol. 2007;20(1):29-37.

22. Thirman MJ, Larson RA. Therapy-related myeloid leukemia. Hematol Oncol Clin North Am. 1996;10(2):293-320

23. Badran A, Yoshida A, Wano Y, Mutoh M, Imamura S, Yamashita T, et al. Expression of the anti-apoptotic gene survivin in myelodysplastic syndrome. Int J Oncol. 2003;22(1):59-64.

24. Mihara K, Chowdhury M, Nakaju N, Hidani S, Ihara A, Hyodo H, et al. Bmi-1 is useful as a novel molecular marker for predicting progression of myelodysplastic syndrome and patient prognosis. Blood. 2006;107(1):305-8.

25. Gianelli U, Fracchiolla NS, Cortelezzi A, Pellegrini C, Savi F, Moro A, et al. Survivin expression in "low-risk" and "high-risk" myelodysplastic syndromes. Ann Hematol. 2007;86(3):185-9.

26. Yamamoto K, Abe S, Nakagawa Y, Suzuki K, Hasegawa M, Inoue $\mathrm{M}$, et al. Expression of IAP family proteins in myelodysplastic syndromes transforming to overt leukemia. Leuk Res. 2004;28(11):1203-11.

27. Youle RJ, Strasser A. The BCL-2 protein family: opposing activities that mediate cell death. Nat Rev Mol Cell Biol. 2008;9(1):47-59.

28. Tsujimoto Y, Cossman J, Jaffe E, Croce CM. Involvement of the bcl-2 gene in human follicular lymphoma. Science. 1985; 228 (4706):1440-3.

29. Delia D, Aiello A, Soligo D, Fontanella E, Melani C, Pezzella F, et al. bcl-2 proto-oncogene expression in normal and neoplastic human myeloid cells. Blood. 1992;79(5):1291-8.

30. Parker JE, Mufti GJ, Rasool F, Mijovic A, Devereux S, Pagliuca A. The role of apoptosis, proliferation, and the Bcl-2-related proteins in the myelodysplastic syndromes and acute myeloid leukemia secondary to MDS. Blood. 2000;96(12):3932-8.

31. Dimri GP, Martinez JL, Jacobs JJ, Keblusek P, Itahana K, Van Lohuizen $\mathrm{M}$, et al. The Bmi-1 oncogene induces telomerase activity and immortalizes human mammary epithelial cells. Cancer Res. 2002;62(16):4736-45.

32. Leung C, Lingbeek M, Shakhova O, Liu J, Tanger E, Saremaslani P, et al. Bmi1 is essential for cerebellar development and is overexpressed in human medulloblastomas. Nature. 2004;428 (6980):337-41.

33. Raaphorst FM, Meijer CJ, Fieret E, Blokzijl T, Mommers E, Buerger $\mathrm{H}$, et al. Poorly differentiated breast carcinoma is associated with increased expression of the human polycomb group EZH2 gene. Neoplasia. 2003;5(6):481-8.
34. Vonlanthen S, Heighway J, Altermatt HJ, Gugger M, Kappeler A, Borner MM, et al. The bmi-1 oncoprotein is differentially expressed in non-small cell lung cancer and correlates with INK4A-ARF locus expression. Br J Cancer. 2001;84(10):1372-6.

35. Beà S, Tort F, Pinyol M, Puig X, Hernández L, Hernández S, et al. BMI-1 gene amplification and overexpression in hematological malignancies occur mainly in mantle cell lymphomas. Cancer Res. 2001;61(6):2409-12.

36. Dukers DF, van Galen JC, Giroth C, Jansen P, Sewalt RG, Otte AP, et al. Unique polycomb gene expression pattern in Hodgkin's lymphoma and Hodgkin's lymphoma-derived cell lines. Am J Pathol. 2004;164(3):873-81.

37. Vvan Kemenade FJ, Raaphorst FM, Blokzijl T, Fieret E, Hamer KM, Satijn DP, et al. Coexpression of BMI-1 and EZH2 polycombgroup proteins is associated with cycling cells and degree of malignancy in B-cell non-Hodgkin lymphoma. Blood. 2001;97 (12):3896-901.

38. Zhang P, Iwasaki-Arai J, Iwasaki H, Fenyus ML, Dayaram T, Owens $\mathrm{BM}$, et al. Enhancement of hematopoietic stem cell repopulating capacity and self-renewal in the absence of the transcription factor C/EBP alpha. Immunity. 2004;21(6):853-63.

39. Borst P, Evers R, Kool M, Wijnholds J. A family of drug transporters: the multidrug resistance-associated proteins. J Natl Cancer Inst. 2000;92(16):1295-302.

40. Jordan MA, Wilson L. Microtubules as a target for anticancer drugs. NNat Rev Cancer. 2004;4(4):253-65.

41. Suárez L, Vidriales MB, García-Laraña J, Sanz G, Moreno MJ, López A, et al. CD34+ cells from acute myeloid leukemia, myelodysplastic syndromes, and normal bone marrow display different apoptosis and drug resistance-associated phenotypes. Clin Cancer Res. 2004;10(22):7599-606.

42. Sonneveld P. Multidrug resistance in haematological malignancies. J Intern Med. 2000;247(5):521-34.

43. Covelli A. Modulation of multidrug resistance (MDR) in hematological malignancies. Ann Oncol. 1999;10 Suppl 6:53-9.

44. Poulain S, Lepelley P, Preudhomme C, Cambier N, Cornillon J, Wattel E, et al. Expression of the multidrug resistance-associated protein in myelodysplastic syndromes. Br J Haematol. 2000; 110 (3):591-8.

45. Lepelley P, Poulain S, Grardel N, Preudhomme C, Cosson A, Fenaux P. Expression of lung resistance protein and correlation with other drug resistance proteins and outcome in myelodysplastic syndromes. Leuk Lymphoma. 1998;29(5-6):547-51.

46. Valera ET, Scrideli CA, Queiroz RG, Mori BM, Tone LG. Multiple drug resistance protein (MDR-1), multidrug resistance-related protein (MRP) and lung resistance protein (LRP) gene expression in childhood acute lymphoblastic leukemia. Sao Paulo Med J. 2004;122(4):166-71.

47. Ogata K, Kishikawa Y, Satoh C, Tamura H, Dan K, Hayashi A. Diagnostic application of flow cytometric characteristics of CD34+ cells in low-grade myelodysplastic syndromes. Blood. 2006; 108 (3):1037-44.

48. Matarraz S, López A, Barrena S, Fernandez C, Jensen E, Flores J, et al. The immunophenotype of different immature, myeloid and B-cell lineage-committed CD34+ hematopoietic cells allows discrimination between normal/reactive and myelodysplastic syndrome precursors. Leukemia. 2008;22(6):1175-83.

49. Della Porta MG, Malcovati L, Invernizzi R, Travaglino E, Pascutto C, Maffioli M, et al. Flow cytometry evaluation of erythroid dysplasia in patients with myelodysplastic syndrome. Leukemia. 2006;20(4):549-55.

50. Kussick SJ, Fromm JR, Rossini A, Li Y, Chang A, Norwood TH, et al. Four-color flow cytometry shows strong concordance with 
bone marrow morphology and cytogenetics in the evaluation for myelodysplasia. Am J Clin Pathol. 2005;124(2):170-81.

51. Orfao A, Ortuño F, de Santiago M, Lopez A, San Miguel J. Immunophenotyping of acute leukemias and myelodysplastic syndromes. Cytometry A. 2004;58(1):62-71.

52. Olney HJ, Le Beau MM. Evaluation of recurring cytogenetic abnormalities in the treatment of myelodysplastic syndromes. Leuk Res. 2007;31(4):427-34.

53. Korgaonkar S, Babu VR, Kerketta L, Ghosh K. Chromosomal breakage in myelodysplatic syndrome. Asian Pac J Cancer Prev. 2008;9(1):151-4.

54. Smith SM, Le Beau MM, Huo D, Karrison T, Sobecks RM, Anastasi $\mathrm{J}$, et al. Clinical-cytogenetic associations in 306 patients with therapy-related myelodysplasia and myeloid leukemia: the University of Chicago series. Blood. 2003;102(1):43-52.

55. Swolin B, Rödjer S, Westin J. Therapy-related patterns of cytogenetic abnormalities in acute myeloid leukemia and myelodysplastic syndrome post polycythemia vera: single center experience and review of literature. Ann Hematol. 2008;87 (6):467-74

56. Magalhães SMM. Síndromes mielodisplásicas: diagnóstico de exclusão. Rev. Bras. Hematol. Hemoter. 2006;28(3):175-177.

57. Apa AG, Gutz CNRM. Fatores prognósticos nas síndromes mielodisplásicas. Rev. Bras. Hematol. Hemoter. 2006;28(3):198200

Suporte Financeiro: CNPq (MCT/CNPq 15/2007) e Capes.

Avaliação: Editor e dois revisores externos

Recebido: 16/12/2008

Aceito: 20/01/2009 